\title{
Evaluation of cellulosic pulps treated by hornification as reinforcement of cementitious composites
}

\author{
Julian Eduardo Mejia Ballesteros ${ }^{\mathrm{a}, *}$, Sergio Francisco Santos ${ }^{\mathrm{b}}$, Gonzalo Mármol a , Holmer Savastano Jr. ${ }^{\mathrm{a}}$, \\ Juliano Fiorelli ${ }^{a}$ \\ ${ }^{a}$ University of São Paulo - Faculty of Animal Science and Food Engineering, Department of Biosystems Engineering, Duque de Caxias Norte Street, 225, 13630-000 Pirassununga, \\ SP, Brazil \\ ${ }^{\mathrm{b}}$ State University of São Paulo - Faculty of Engineering, Department of Materials and Technology, Ariberto Pereira da Cunha, 333, 12516-410 Guaratinguetá, SP, Brazil
}

\section{H I G H L I G H T S}

- Hornification treatment does not deteriorate the fiber quality.

- Hornificated pulps show good behavior as reinforcement for composites at early ages.

- Hornification process presents potential to be used as a treatment for cellulosic pulps.

\section{A R T I C L E I N F O}

\section{Article history:}

Received 11 December 2014

Received in revised form 25 August 2015

Accepted 24 September 2015

Available online 8 October 2015

\section{Keywords:}

Cellulosic pulps

Cement-based matrix

Durability

Hornification

Reinforcement

\begin{abstract}
A B S T R A C T
This study evaluated the effect of the hornification process on cellulosic fibers of bleached pine and unbleached eucalyptus with in order to improve its durability and volume stability to be used as reinforcement in cementitious matrices. The study indicated that the treatment did not deteriorate the properties of viscosity and index of crystallinity and decreased the capacity of water retention. Composites reinforced with hornificated and untreated pulps with thermal curing or accelerated aging were produced and evaluated to assess their physical and mechanical behavior. The use of hornificated fibers as reinforcement generated improvements in the modulus of rupture and specific energy of the composites.
\end{abstract} (c) 2015 Elsevier Ltd. All rights reserved.

\section{Introduction}

It is well known that construction industry is responsible for solid waste production, large consumption of non-renewable resources for several materials production and release of green house effect gases to the atmosphere [1,2], being responsible for the generation of approximately $30 \%$ of $\mathrm{CO}_{2}$ world emissions [2]. Thus, a necessity of minimizing environmental and health problems arose which stimulated different research studies to develop new materials from alternative raw material sources, remarking vegetable fibers as reinforcement materials in cementitious matrices $[3,4]$. The use of this type of fiber generated great interest by offering a wide number of advantages, which stands its low cost when compared to synthetic fibers, high availability, low density, renewable resource nature and solid waste reuse [3]. In addition,

\footnotetext{
* Corresponding author.

E-mail address: julian.mejia@usp.br (J.E.M. Ballesteros).
}

composites made from these fibers have shown good performance of thermal properties [5].

The use of long fibers (e.g. Pinus) as reinforcement is common in fiber cement products on the current market [6]. These fibers generally perform better than short fibers (e.g. Eucalyptus) $[7,8]$, as they have higher anchorage length. Moreover, they are thicker fibers with thick cell walls and therefore, they are stronger compared to fibers with thin cell walls [8]. Regarding short fibers, its use is economically more favorable [6], their lower fiber length allows a higher concentration of fibers per gram, improving their dispersion and distribution within the matrix [9], favoring the performance of the material.

The reinforced composites have a different behavior compared to not reinforced composites when its maximum tensile strength is overcome. The latter show an abrupt break with null strain, typical for brittle materials. The main purpose of reinforcing fragile cement matrices from plant fibers is to obtain a better mechanical performance for the composite in practical applications [10]. The 
material must display superior functional characteristics when compared with the conventional material, for example, an increase in flexural strength reaching a ductile behavior, greater energy absorption capacity before failure, cracking control and prevention. It also allows the use of the material in post-cracked conditions [11] and a better fatigue and thermal conductivity resistance [12]. Several studies showed positive results regarding the performance of cementitious matrices reinforced with vegetable fibers [13-15].

However, the use of vegetable fibers as reinforcement in cementitious composites exhibits some drawbacks associated to two factors which are considered crucial: (1) degradation of the fiber constituents (lignin and hemicellulose) and reduction of the degree of polymerization in the alkaline environment of the matrix and (2) physical incompatibility (lack of adherence) between the fibers and the matrix in relation to dimensional variations of the fibers by its hygroscopicity. The decrease in the degree of reinforcement in the composites can be attributed to the decrease in fiber pullout, being this decrease explained by several factors working in conjunction, such as weakening of the fibers caused by the alkaline attack, mineralization of the fibers by migration of cement hydration products to the core of the fibers and generated gaps by fiber dimensional change [16].

Several alternatives to extend the life of the plant fibers can be based either on the fiber processing or on modification of the cementitious matrix $[17,18]$. The hornification treatment arises as a pre-treatment of the fibers. Hornification is a technical term to describe changes and structural alterations in the cellulosic fibers originated from either dewatering or recycling of the fibrous pulp [19]. During the hornification process, inside the fibers, the fibrils are in contact after drying [20] and the cellulose polysaccharide chains are grouped closely together (firm packaging) with water removal [21], causing the binding of microfibrils as a flat strip $[22,23]$. This all leads to the irreversible loss of water retention capacity of the fibers $[22,24]$ and the collapse of the vegetable fiber without dramatically altering their strength properties $[25,26]$.

The reduction of the water retention capacity of the cellulosic fibers may have beneficial effects when incorporated as a reinforcement for cement matrices, since these fibers have greater dimensional stability, providing better adhesion between fibermatrix and reducing the formation of fouling hydroxide calcium on the surface and lumen of the fibers, resulting in a reduction in the degradation of cellulose in the cement matrix [27].

In this study, physical-mechanical performance of cement matrices reinforced with unbleached eucalyptus and bleached pine pulp hornificated by four drying and wetting cycles was analyzed. The physical-mechanical behavior of composites was evaluated after thermal curing and 200 accelerated aging cycles.

\section{Materials and methods}

\subsection{Materials}

Unbleached hardwood kraft pulp of eucalyptus (Eucalyptus grandis e Eucalyptus urophylla) and commercial bleached softwood kraft pulp of pine (Pinus radiata) supplied by private companies were used as a reinforcement. Unbleached eucalyptus pulp (UnBE) was taken at the beginning of the bleaching process and disintegrated with $65 \%$ relative humidity and bleached pine pulp (BP) was presented in a dry sheet form with $10 \%$ relative humidity. As cementitious matrix high early strength Portland cement (CPV-ARI) according to ASTM-C150 Standard [28] and limestone were used. The oxide composition of the components of the matrix is showed in Table 1.

\subsection{Pulp treatment}

The hornification process of the pulps consisted of four cycles of drying and rewetting, as follows: (1) pulp drying in an oven with air circulation at $60^{\circ} \mathrm{C}$ for $7 \mathrm{~h}$; (2) rewetting by immersion in water at room temperature for $15 \mathrm{~h}$; (3) disin-
Table 1

$\mathrm{X}$-ray fluorescence chemical analysis of the cementitious matrix materials in mass percentage.

\begin{tabular}{lll}
\hline Oxide composition & Portland cement $-\mathrm{CP}$ V-ARI & Limestone \\
\hline $\mathrm{CaO}$ & 63.5 & 51.7 \\
$\mathrm{MgO}$ & 2.32 & 3.04 \\
$\mathrm{SiO}_{2}$ & 19.1 & 1.70 \\
$\mathrm{Al}_{2} \mathrm{O}_{3}$ & 4.44 & 0.21 \\
$\mathrm{Fe}_{2} \mathrm{O}_{3}$ & 2.68 & 0.17 \\
$\mathrm{Na}_{2} \mathrm{O}$ & 0.36 & 0.01 \\
$\mathrm{~K}_{2} \mathrm{O}$ & 1.10 & 0.09 \\
$\mathrm{SO}_{3}$ & 2.63 & - \\
$\mathrm{MnO}^{\mathrm{P}_{2} \mathrm{O}_{5}}$ & $<0.10$ & 0.04 \\
$\mathrm{TiO}_{2}$ & 0.21 & 0.08 \\
Loss on ignition $\left(1000^{\circ}\right)$ & 0.24 & 0.03 \\
\hline
\end{tabular}

tegration of wet cellulose pulp in a disintegrator (3.000 revolutions - $10 \mathrm{~min}$ ) according Ref. [29]; (4) pulp suspension filtering through a Buchner funnel equipped with a wire screen (150 mesh). At the end of the process (after 4 cycles) the fibers were stored in sealed plastic bags until their subsequent use. The hornification methodologies was taken and modified from Claramunt et al. [27].

\subsection{Pulp characterization}

\subsubsection{Water retention value}

The water retention values were determined after and before the hornification process according to the standard Tappi UM 256 [30].

\subsubsection{X-ray diffractometry}

To measure the crystallinity index of the cellulose pulp before and after the treatment, the technique of X-ray diffractometry (XRD) was used. The crystallinity index of cellulose pulps was determined according to the empirical method suggested by Segal, [31]. This method consists in calculating the index of crystallinity for cellulose (Cr.I.), according to the following Eq. (1):

Cr.I. : $\frac{l_{002}-l_{\mathrm{am}}}{l_{002}} \times 100$

where $l_{002}$ corresponds to the maximum intensity of diffraction (crystalline) of plane (002) and $l_{\mathrm{am}}$ refers to the intensity of the background scatter (amorphous). The values $l_{002}$ and $l_{\text {am }}$ were obtained directly from diffractograms of studied pulp.

\subsubsection{Viscosity measurements}

The viscosity measurements were determined after and before the hornification process according to the standard Tappi 230 om-04. [32]

\subsection{Composites production}

4 sets of samples composed of 16 specimens each were prepared. The purpose of this stage was to evaluate the behavior of composites reinforced with bleached and unbleached hornificated and untreated fibers, according to their mechanical properties and durability of the fibers before and after the accelerated aging test. One set was prepared with untreated pulp and the other one with hornificated pulp. 8 specimens of each series were subjected to accelerated aging treatment. The experimental composition of the specimens was fixed in mass percentages as follows: $68 \%$ cement, $27 \%$ limestone and $5 \%$ pulp.

For the production and characterization of the composites, flat plates of cement with dimensions of $200 \times 200 \times 5 \mathrm{~mm}$ were molded. The production method is based on raw materials mixing with an excess of water that is removed by vacuum drainage and subsequent mechanical pressing ( $3.5 \mathrm{MPa}$ for $5 \mathrm{~min}$ ) according to the procedure described by Savastano et al. [33]. Dried pulps were previously dispersed in water by means of a pulp disintegrator at $3000 \mathrm{rpm}$ for $10 \mathrm{~min}$. Other inputs were added and homogenized for another $10 \mathrm{~min}$ using a high speed mechanical stirrer $(1700 \mathrm{rpm})$. The formed suspension was transferred to a molding chamber. For each formulation, plates were pressed individually, and sealed in plastic bags in saturated conditions for two days and then submitted to thermal curing (controlled environment of $90 \% \mathrm{RH}$ and $55^{\circ} \mathrm{C}$ ) for 5 days. Upon completion of the cure the plates were cut into four specimens $(160 \times 40 \mathrm{~mm})$ with water cooled diamond saw. Series consisting of 8 specimens for each formulation were tested in the saturated conditions (immersed in water $24 \mathrm{~h}$ before mechanical testing) and another series of 8 specimens were intended to accelerate aging. 


\subsection{Mechanical and physical characterization}

The eight specimens obtained from flat plates were subjected to physical tests to determine the properties water absorption (WA), bulk density (BD) and apparent void volume (AVV) according to ASTM C-948-81 Standard [34]. Mechanical properties determination was carried out by means of four point bending tests, using universal testing machine (Emic DL-30000 model), equipped with a $1 \mathrm{kN}$ load cell. The deflection speed used was of $1.5 \mathrm{~mm} / \mathrm{min}$ in order to determine the values of a module of rupture (MOR), limit of proportionality (LOP), module of elasticity (MOE) and specific energy (SE). Setting test were adapted to recommended by RILEM Committee 49 TFR procedure [35] and adapted by Savastano, et al. [33] for determination of specific energy. The test was performed until the decrease in the load carrying capacity to $5 \%$ of the maximum load. The specific deflection was calculated by dividing the deflection by the length of the greater span. For statistical analysis of mechanical and physical proprieties was used a completely randomized design to compare the means and the Tukey test at 0.05 significance level using the program S.A.S 9.3 (Statistical Analysis System).

\subsection{Accelerated aging method}

The specimens were subjected to accelerated aging by a procedure of immersion and drying in order to study the behavior of the cellulosic fibers after aging. This test was adapted from the standard EN 494 Standard [36], and carried out in a climatic chamber, (Marconi, model MA 035). Each cycle of complete immersion in water has a duration of $170 \mathrm{~min}$. Heating cycle to $70 \pm 5^{\circ} \mathrm{C}$ is kept for the same period of time. A complete cycle is represented by a full period of immersion and drying. Between each period of immersion and drying there is an interval of $10 \mathrm{~min}$. The specimens were subjected to 200 cycles of accelerated aging.

\subsection{Microstructural characterization of the reinforced composites}

Samples of composites reinforced with treated and untreated pulp resulting from the mechanical tests after thermal curing and accelerating aging were used. Samples were placed in a low vacuum scanning electron microscope (SEM), brand Hitachi - model TM-3000, coupled with X-rays microanalysis system by energy dispersive spectroscopy. Working with low vacuum allows observing the samples without metallic covering. A voltage of $15 \mathrm{kV}$ was used. The images were formed by acquisition of backscattered electrons at different magnifications.

\section{Results and discussion}

\subsection{Physical-chemical characterization of pulp}

The physical-chemical characterization of the pulps fibers are showed in Table 2.

The results shown in Table 2 indicate that after wetting and drying cycles, mean levels of water retention tended to decrease for all types of pulps as a result of the collapse of its surface and pore volume loss [37]. Similar results after hornification cycles were found by Letkova et al. [38] for kraft pulps bleached eucalyptus, with reductions around $20 \%$ in WRV values.

The effect of repeated wetting and drying cycles caused a decrease in WRV contents for the pulp without treatment, approximately $10 \%$ for BP and approximately $24 \%$ for UnBE. It was expected a further reduction in WRV levels for BP in relation to the absence of lignin and hemicellulose of this kind of pulp, which promotes the formation of strong bonds between cellulose pulp, hindering the access of water [26]. However, the greatest reduction was shown by UnBE fibers, explained by the fact that these fibers had a condition "never before dry" before treatment, therefore, it was expected a greater drop in WRV content.
The crystallinity indices of the pulps obtained from XRD patterns are shown in Table 2. Considering the behavior of crystallinity after four cycles of hornification, an overall decrease in the levels is observed, with reductions of about $10 \%$ for UnBE and $5 \%$ for $\mathrm{BP}$, which can be considered a minimal reduction related to the treatment effects. This statement is confirmed by several authors with similar results with insignificant decrease in crystallinity levels for different types of vegetable pulps subjected to drying and wetting cycles $[39,40]$. Thus, whereas the degree of crystallinity influence the physical and mechanical properties of the fibers [37] and, especially, the elastic modulus [41] it can be concluded that that these fiber properties are kept after treatment.

The results of the viscosity test are shown in Table 2 . This test, commonly employed as an indirect parameter to measure the cellulosic fiber strength, is related to the average degree of polymerization, where reductions indicate a degree of degradation of the components of the fiber. The higher viscosity values are displayed for the UnBE pulp. Viscosity results are consistent and explained by the degradation suffered by the bleached pulps submitted to the pulping and bleaching process [42]. After pulp hornification in all cases a reduction of about $8 \%$ for UnBE and $1 \%$ for BP is observed. The decrease of the degree of polymerization is related to the hornification process of the fiber cell wall, which may cause hydrolytic cleavage of covalent bonds linking one monomer to another [43]. However, this decrease can be considered insignificant and does not negatively influence the performance of the pulps. According Claramunt et al. [26], the lessening of viscosity values about $8 \%$ might be regarded as evidence of an insignificant degradation level that will not negatively affect the pulp strength.

\subsection{Mechanical and physical performance of the composites reinforced with treated fibers}

In Figs. 1 and 2 typical flexural strength vs specific deflection curves are observed. These curves were obtained during the bending test of UnBE and BP reinforced composites with thermal curing

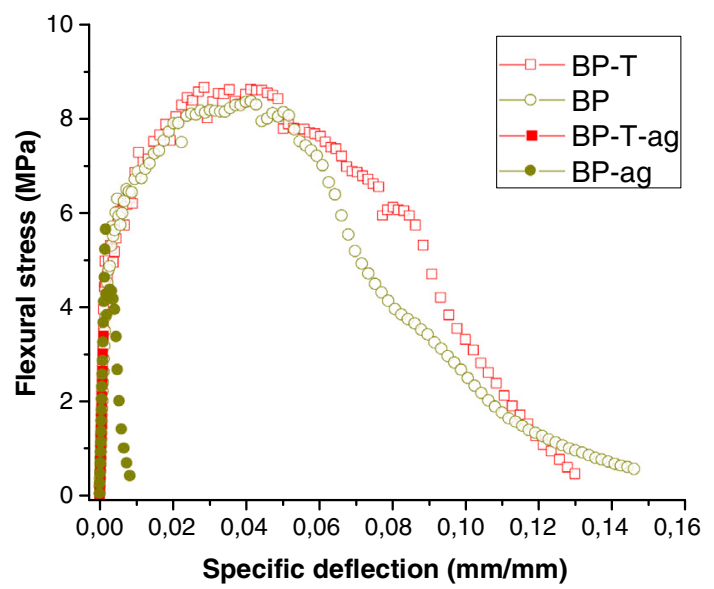

Fig. 1. Typical stress $\times$ strain curves for composites reinforced by bleached pine (BP), bleached pine treated (BP-T), bleached pine aged (BP-ag) and bleached pine treated aged (BP-T-ag).

Table 2

Physical and chemical characterization of cellulosic pulps.

\begin{tabular}{|c|c|c|c|c|}
\hline Cellulosic pulp & Hornification treatment & Water retention value (\%) & Index of crystallinity (\%) & Viscosity $\left(\mathrm{cm}^{3} / \mathrm{g}\right)$ \\
\hline \multirow[t]{2}{*}{ Bleached pine } & 0 cycles & 122.6 & 80.7 & 730 \\
\hline & 4 cycles & 110.6 & 77.0 & 725 \\
\hline \multirow[t]{2}{*}{ Unbleached eucalyptus } & 0 cycles & 221.2 & 81.8 & 919 \\
\hline & 4 cycles & 167.9 & 73.4 & 848 \\
\hline
\end{tabular}




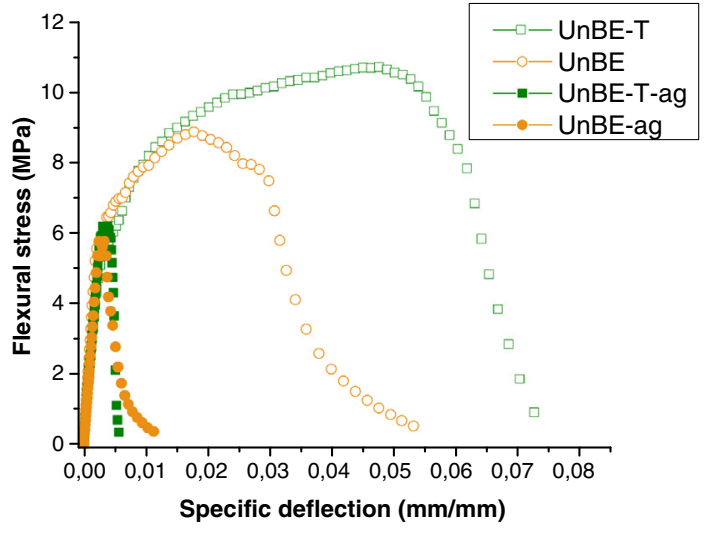

Fig. 2. Typical stress $\times$ strain curves for composites reinforced by unbleached eucalyptus (UnBE), unbleached eucalyptus treated (UnBE-T), unbleached eucalyptus aged (UnBE-ag) and unbleached eucalyptus treated aged (UnBE-T-ag).

and after 200 accelerated aging cycles. It is shown primarily the contribution of the cement matrix in the elastic region until the first cracking phenomenon and after that point the reinforcing effect of vegetable fiber, characterized by the transfer of forces from the matrix to the fibers, which allows up the ductile behavior in the composite in rather than the typical abrupt rupture of fragile cementitious matrices.

Composites reinforced with BP fibers as reinforcement behave similarly to hornificated BP (Fig. 1). Furthermore, similarity can be seen between the maximum strength value and bending energy absorption, indicating that hornification is not deteriorating the fibers to the point of affecting the strength properties though not significant improvement is perceived. Respect for UnBE reinforced composites (Fig. 2), it is noted clearly a better performance for those with treated fibers, resulting in a higher flexural strength (10.6 MPa) compared to reinforced with untreated fibers (8.9 MPa). Also the deformation and energy absorption are superior for hornificated UnBE. Particularly specific energy is approximately $87 \%$ higher for treated $\operatorname{UnBE}\left(4.5 \mathrm{~kJ} / \mathrm{m}^{2}\right)$ than UnBE $\left(2.4 \mathrm{~kJ} / \mathrm{m}^{2}\right)$.

For every type of pulp, after accelerated aging test a loss of reinforcing capacity of the fibers is observed (Figs. 1 and 2) that is represented by the drastic fall of the stress-strain curve immediately after reaching the MOR.

Table 3 shows the average values of the physical properties of water absorption (WA), bulk density (BD) and apparent void volume (AVV), and mechanical properties of modulus of rupture (MOR), the limit of proportionality (LOP), MOR/LOP ratio, modulus of elasticity (MOE), and specific energy (SE) for cementitious composites reinforced with $\mathrm{BP}$ and UnBE pulp, treated and untreated, subjected to thermal curing and accelerated aging (200 cycles).

For unaged composites reinforced with treated and untreated pulps of UnBE, it is observed slight change in the absence of a sig- nificant difference $(p>0.05)$ when applied Tukey test with a significance level of $5 \%$ of the properties WA, BD and AVV, indicating minor influence of the treatment. Otherwise for composites reinforced with BP, it exists significant variation $(p<0.05)$ between treated and untreated fibers.

After accelerated aging process, a trend to decrease in WA and AVV values for BP and UnBE treated and untreated may be seen. In general, as noted in Table 3 , no significant difference appears $(p>0.05)$ for BD values after 200 aging for composites with treated or untreated pulps.

Composites reinforced with UnBE fibers with and without treatment with thermal curing have the highest WA values and one of the highest AVV values when compared with pine fibers. This behavior, according Pehanich et al. [44] can be explained by the greater number of fibers per gram (short fiber) compared to the long fibers, since they lead to a higher porosity due to a larger amount of lumens (more fibers). Even if treated eucalyptus fibers show a higher porosity, high surface roughness generated by hornification treatment can ensure better interface with the cement matrix. The highest WA values were observed for UnBE and UnBE-T, possibly as a result of the increased presence of hemicellulose component that favors the absorption of moisture.

As a consequence of aging cycles a fall in WA and AVV values and a tendency to increase in BD is shown, all in relation to the existing gaps filling in the cement matrix with cement hydration products and fiber-matrix interface modification [45]. According Tonoli et al. [46], accelerated aging cycles favors the reprecipitation and dissolution of cement hydration products around the fibers or inside of them, causing a reduction of said porosity.

Hornificated fibers showed the highest values of WA and AVV, a situation explained by their morphology, since the collapse and the greater roughness of these fibers can impede the drainage of water during the production stage of the composite.

In previous studies conducted by Tonoli et al. [46], for composites reinforced with eucalyptus pulps chemically treated to modify its surface (6\% by weight), values between $16.4 \%$ and $17.7 \%$ of WA, $29.0 \%$ and $30.8 \%$ of $\mathrm{AVV}$ and 1.75 and $1.79 \mathrm{~g} / \mathrm{cm}^{3}$ of $\mathrm{BD}$ were obtained, and after 200 accelerated aging cycles values ranging from $13.5 \%$ to $16.2 \%$ of WA, $24.6-27.9 \%$ of AVV and $1.72-1.83 \mathrm{~g} /$ $\mathrm{cm}^{3}$ of BD were obtained, so no significant differences were observed in physical properties compared to fibers used for either case.

The results indicate that the average levels of physical properties are close to those found in the literature. Furthermore, it is noteworthy that the WA values for the different formulations are below $37 \%$, and this percentage the limit established by the NBR 5640 [47], so it may considered that the average values of this property are acceptable.

For mechanical properties as shown in Table 3 and Figs. 1 and 2, when compared to composites reinforced with the same type of pulp treated and untreated, no significant variation is observed $(p>0.05)$. Before the cracking of the matrix, regarding the LOP, it is unclear significant treatment effect $(p>0.05)$ for any of the cases

Table 3

Physical and mechanical properties of composites reinforced by pine and eucalyptus treated (T) and untreated with thermal curing or aging (ag)

\begin{tabular}{|c|c|c|c|c|c|c|c|c|}
\hline Cellulosic pulp & WA (\%) & $\operatorname{AVV}(\%)$ & $\mathrm{BD}\left(\mathrm{g} \mathrm{cm}^{-3}\right)$ & MOR (MPa) & LOP (MPa) & MOE (GPa) & Specific energy $\left(\mathrm{kJ} \mathrm{m}^{-2}\right)$ & MOR/LOP \\
\hline $\mathrm{BP}$ & $18.4 \pm 1.1 \mathrm{a}$ & $31.7 \pm 1.1 b$ & $1.72 \pm 0.05 a$ & $8.7 \pm 0.5 a$ & $4.7 \pm 0.7 a$ & $10.6 \pm 1.2 \mathrm{a}$ & $4.3 \pm 1.1 \mathrm{a}$ & $1.9 \mathrm{a}$ \\
\hline BP-ag & $16.4 \pm 0.4 c$ & $28.2 \pm 0.8 c$ & $1.73 \pm 0.02 a$ & $5.5 \pm 1.0 \mathrm{~b}$ & $4.8 \pm 1.4 a$ & $11.9 \pm 2.8 \mathrm{ab}$ & $0.1 \pm 0.1 b$ & $1.2 \mathrm{bc}$ \\
\hline BP-T & $20.5 \pm 0.3 a$ & $33.6 \pm 0.2 \mathrm{a}$ & $1.64 \pm 0.01 b$ & $8.5 \pm 1.1 \mathrm{a}$ & $5.0 \pm 0.8 a$ & $12.1 \pm 1.6 \mathrm{ab}$ & $4.4 \pm 1.0 \mathrm{a}$ & $1.7 \mathrm{ab}$ \\
\hline BP-T-ag & $18.3 \pm 0.1 b$ & $30.1 \pm 0.3 b$ & $1.64 \pm 0.01 b$ & $3.6 \pm 0.8 c$ & $3.6 \pm 0.8 a$ & $13.7 \pm 1.5 b$ & $0.02 \pm 0.1 b$ & $1.0 \mathrm{c}$ \\
\hline UnBE & $20.9 \pm 0.7 a$ & $32.9 \pm 0.6 a$ & $1.57 \pm 0.03 a$ & $8.9 \pm 1.0 \mathrm{a}$ & $5.0 \pm 0.5 a$ & $9.9 \pm 1.2 \mathrm{a}$ & $2.4 \pm 0.6 a$ & $1.8 \mathrm{~b}$ \\
\hline UnBE-ag & $17.2 \pm 1.1 b$ & $27.5 \pm 1.3 b$ & $1.6 \pm 0.06 a$ & $5.7 \pm 0.6 c$ & $5.3 \pm 1.0 \mathrm{a}$ & $10.4 \pm 0.9 a$ & $0.1 \pm 0.1 c$ & $1.1 \mathrm{c}$ \\
\hline UnBE-T & $21.1 \pm 0.7 a$ & $33.3 \pm 0.6 a$ & $1.58 \pm 0.03 a$ & $10.6 \pm 0.9 b$ & $4.6 \pm 0.5 a$ & $9.1 \pm 1.0 \mathrm{a}$ & $4.5 \pm 1.0 \mathrm{~b}$ & $2.3 a$ \\
\hline UnBE-T-ag & $17.5 \pm 0.4 b$ & $27.7 \pm 0.2 b$ & $1.59 \pm 0.03 a$ & $6.0 \pm 1.1 \mathrm{c}$ & $4.5 \pm 1.0 \mathrm{a}$ & $9.2 \pm 1.5 a$ & $0.2 \pm 0.1 \mathrm{c}$ & $1.3 \mathrm{c}$ \\
\hline
\end{tabular}

"Values with different letters in the same column have statistical difference from Tukey test $(p<0.05)$. 

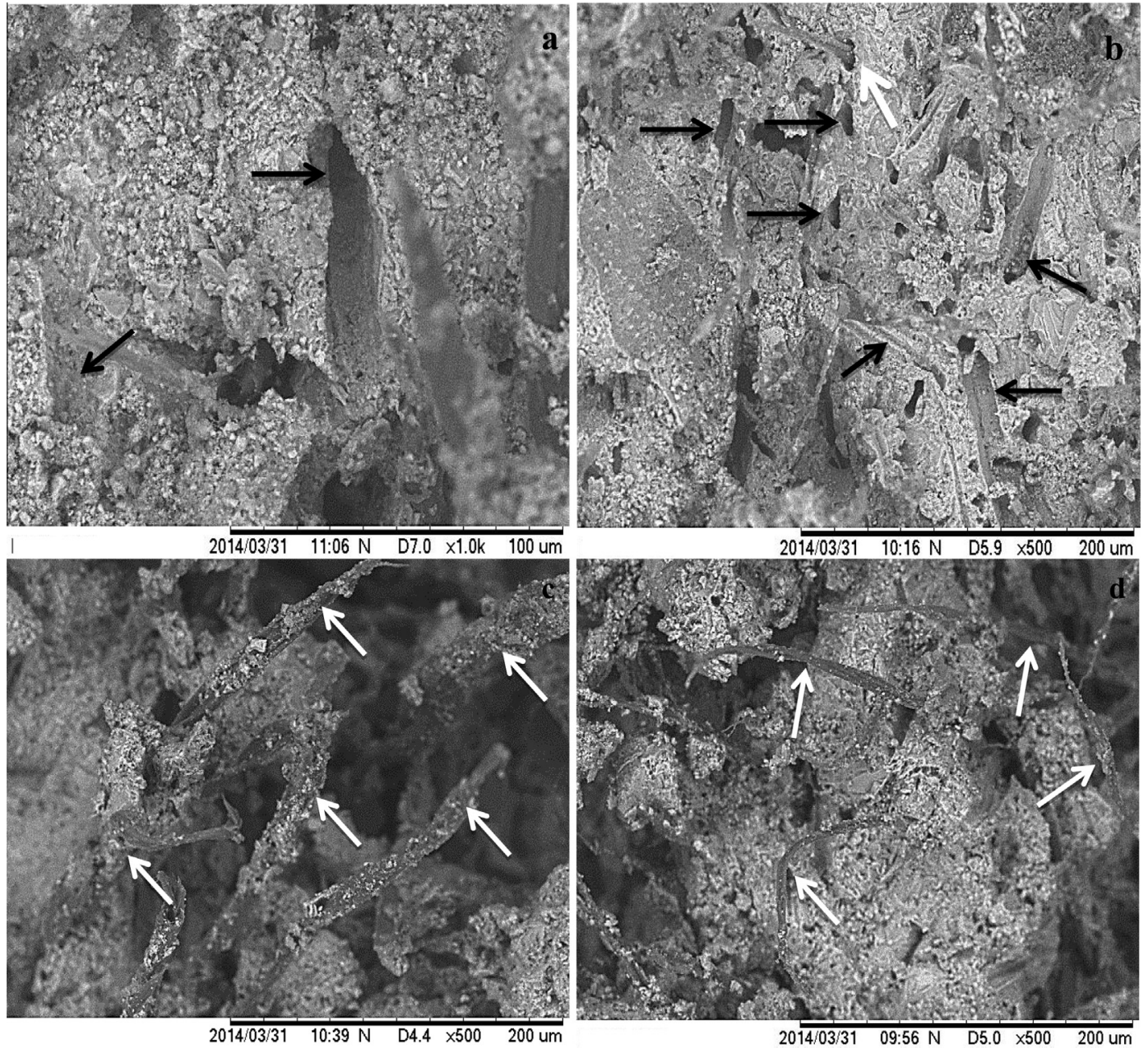

Fig. 3. Micrographies of fracture surface of composites thermal cured and reinforced with pulps of BP (a), UnBE (b), BP-T (c), and UnBE-T (d).

in this study. Similar behavior was observed for the MOE. The MOR/LOP ratio showed no significant changes for BP. For UnBE a significant increase is noted for composites with treated fibers indicating a better performance of the fiber as reinforcement.

For MOR, variation is observed of approximately 3\% between the average values of composites reinforced with treated and untreated pulp BP. For composites reinforced with UnBE a significant increase $(p<0.05)$ in MOR of about $19.4 \%$ is shown. This result may have been influenced by the viscosity and a greater hornification degree (Table 2), as well as improved fiber-matrix interface and better distribution.

Considering the length of the fiber to SE ratio, the composites reinforced with $B P$ have the highest values. Thus, a stress which causes a debonding of the fiber from the matrix produces a large friction on the interface, so the energy required to collapse a reinforced composite is directly proportional to the length of the reinforcing fiber [48]. After hornification treatment an increase in SE levels of approximately $3 \%$ for BP samples and $87.5 \%$ for UnBE is achieved. The best results for hornificated UnBE may be related to the best distribution in the matrix and the rougher the surface thereof as compared with the BP pulp, thus generating proper anchoring and performance after matrix cracking.

According to Claramunt et al. [27], cementitious composites reinforced with modified pine pulp and cotton by four cycles of drying and wetting showed an increase in toughness of approximately $20 \%$ for pine pulp samples and $5 \%$ for cotton, compared to untreated fiber composites.
The significant increase in SE and MOR for composites reinforced with UnBE after thermal curing suggests that this type of pulp has the best mechanical performance before aging. Therefore, this behavior may indicate a favorable interface between the fiber and the cement matrix [49].

When subjected to accelerated aging, the composite showed a reduction of the MOR values with statistical significance $(p<0.05)$ for all types of fiber, as can be seen in Table 3 .

The composites with untreated fibers showed a slight increase in the value of the LOP, whereas composites with treated pulp presented a slight reduction. There was no significant variation $(p>0.05)$ for any of the cases. Similar results were presented by Tonoli et al. [46] for aged composites (200 cycles) and reinforced with silane-modified pulps, where not variation of LOP was observed by the influence of the modification of the fiber.

The MOR/LOP ratio decreases without significant differences $(p>0.05)$ between the different formulations, indicating deterioration of reinforcing capacity. The MOE values show a slight tendency to increase, without any statistical significance $(p>0.05)$. This trend relates to continuous aging cycles that cause densification of the composite, increasing the fiber-matrix adhesion and promoting further hydration of the cementitious matrix [46].

For SE, it is observed an intense decrease of the values of this property, with over $90 \%$ reductions in all cases. As stated by Tonoli et al. [49] the decline of toughness is presented as a function of dissolution and re-precipitation of the hydration products that generates an improved fiber-matrix adhesion and brings on fiber 

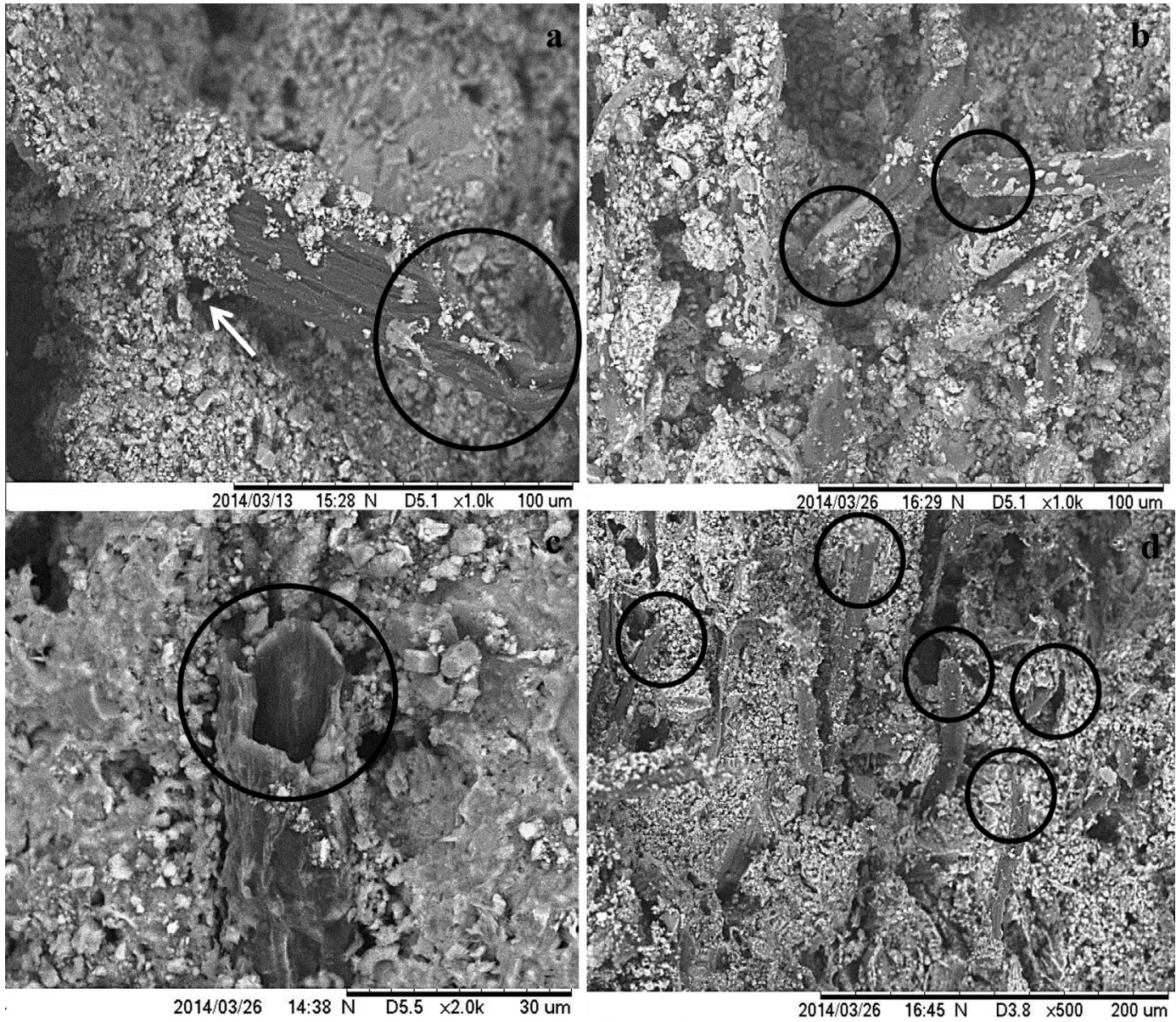

Fig. 4. Micrographies of fracture surface of composites after accelerated aging reinforced with pulps of BP-ag (a), UnBE-ag (b), BP-T-ag (c), and UnBE-T-ag (d).

breaking instead of pullout, hence the rougher surface of treated fibers in addition to the deterioration of fiber quality contributed to the drop in toughness. When comparing the mean values of the composites reinforced with the same type of treated and untreated fibers, there is no statistical deference $(p>0.05)$.

According to Claramunt et al. [27], for hornificated unbleached pine pulps, the results for non-treated pine showed a decrease of MOR (23\%) and SE (71\%). For treated pulp a decrease of MOR (20\%) and SE (48\%) was shown. These results indicate better preservation of the properties of the treated fibers reinforced composites as compared to the current study. Thus, this situation can be explained by the difference in accelerated aging processes used.

According to the NBR 15498 Standard [50] for flat plates of asbestos-free fiber-cement tested in saturated state, values of MOR of 4 as Category 2 and from $7 \mathrm{MPa}$ as Category 3. So after accelerated aging test ( 200 cycles), the composites produced with treated or untreated pulp were classified in Category 2.

\subsection{Microstructural characterization of the reinforced composites}

SEM micrographs for fractured surfaces of cement composites reinforced with untreated and hornificated UnBE and BP fibers and subjected to thermal curing are shown in Fig. 3.

In Fig. 3a and b, a higher incidence of detachment of the cementitious matrix fibers is observed, possibly as a consequence of hygroscopic fibers variations. This detachment, pointed by black arrows, when it occurs, leaves empty spaces where previously occupied by the fibers. The white arrows indicate a low-adhesion fiber-matrix interface.
In Fig. $3 \mathrm{c}$ and $\mathrm{d}$ a better matrix-fiber adhesion is perceived and a pullout of fibers treated after thermal curing is revealed, as indicated by the white arrows. This event may be explained as a result of the less dimensional variation of the treated fibers as a consequence of its lower water absorption capacity, as evidenced in the WRV tests (Table 2).

The trend to increase SE for composites reinforced with hornificated BP and UnBE, and MOR for hornificated UnBE can corroborate the hypothesis of a better adhesion between fiber and matrix, enhancing the gradual pullout of fibers.

SEM micrographs for fractured surfaces of cement composites reinforced with untreated and hornificated UnBE and BP fibers and subjected to accelerate aging are shown in Fig. 4.

In the micrographs of aged composites reinforced with untreated fibers (Fig. 4a and b), fractured fibers (circles) and some degree of adhesion loss fiber-matrix (arrow) are noticed. With respect to composites reinforced with treated fibers (Fig. 4c and d) it is displayed a greater amount of fiber fracture and a lower loss of adhesion when compared to untreated fibers.

This can be explained due to the higher fiber-matrix adhesion exceeding the tensile strength of the fiber, resulting in its fracture or break instead of pulling-out $[45,49]$ and an SE decrease, since the amount of energy absorbed during the pull-out is greater than that absorbed during the break. The decrease in WA and AVV after aging (Table 3), can be attributed to the voids filing within the matrix and alterations of the fiber-matrix interface. Thus, a matrix with higher AVV may favor fiber pull-out, while a less porous matrix may promote fiber break [51]. The composites with hornificated fibers showed the highest values of WA and AVV, indicating a possible increase in fiber-matrix adhesion. 
As shown in Fig. 4, neither cement hydration products are found filling the lumens of the fibers nor severe deterioration of the surfaces thereof.

\section{Conclusions}

When assessing the effect of hornification treatment on BP and UnBE pulps by observing the crystallinity index and viscosity characteristics, it is noted that the process does not generate any significant change to the studied fibers.

The hornification process resulted in a reduction in water retention values for all the pulps, being this effect more significant on the UnBE pulp (24\%) compared with BP (10\%). This result indicates a loss of the swelling capacity of the fiber and thus greater dimensional stability and improved adhesion fiber-matrix.

Composites reinforced with hornificated UnBE and BP fibers after thermal curing, showed no significant changes in physical properties (WA, AVV, BD) compared to those reinforced with untreated fibers. After accelerated aging test (200 cycles) decreasing of WA and AVV were observed, which can be explained by the filling of the voids in the matrix and the interface between fiber and matrix with the hydration products.

For SE, an increase was observed for all formulations with treated reinforcing fibers. Treated UnBE stood out as the reinforcing fiber that generated the best mechanical performance composites, leading to significant improvements in the properties of MOR and SE. This result can be attributed to greater degrees of hornification obtained by this fiber, in addition to being the only virgin fiber of the study. Subsequent to accelerated aging, all formulations showed a drop of MOR and SE, while MOE increased, indicating the matrix densification reducing the material toughness due to the predominance of fibers break instead of its progressive pullout from the matrix.

\section{Acknowledgments}

The authors were supported by Grants offered by Susano Papelcelulose S.A., Brazil.

\section{References}

[1] K.L. Mok, S.H. Han, S. Choi, The implementation of clean development mechanism (CDM) in the construction and built environment industry, Energy Policy 65 (2014) 512-523.

[2] F. Pacheco-Torgal, S. Jalali, Cementitious building materials reinforced with vegetable fibres: a review, Constr. Build. Mater. 25 (2011) 575-581.

[3] M.H. Ishizaki, L.L.Y. Visconte, C.R.G. Furtado, M.C.A.M. Leite, J.L. Leblanc Caracterização mecânica e morfológica de compósitos de polipropileno e fibras de coco verde: influência do teor de fibra e das condições de mistura, Polímeros 16 (2006) 182-186.

[4] S.M. Hejazi, M. Sheikhzadeh, S.M. Abtahi, A. Zadhoush, A simple review of soil reinforcement by using natural and synthetic fibers, Constr. Build. Mater. 30 (2012) 100-116.

[5] G.H.D. Tonoli, S.F. Santos, J.Á. Rabi, W.N. Santos, J.H. Savastano, Thermal performance of sisal fiber-cement roofing tiles for rural constructions, Sci Agricola 68 (2011) 1-7.

[6] G.H.D. Tonoli, E. Fuente, C. Monte, H.J. Savastano, L.F.A. Rocco, A. Blanco, Effect of fibre morphology on flocculation of fibre-cement suspensions, Cem. Concr. Res. 39 (2009) 1017-1022.

[7] D.D.L. Chung, Dispersion of short fibers in cement, J. Mater. Civ. Eng. 17 (2005) $379-383$.

[8] J.H. Morton, T. Cooke, S.A.S. Akers, Performance of slash pine fibers in fiber cement products, Constr. Build. Mater. 24 (2010) 165-170.

[9] R. Jarabo, E. Fuente, M.C. Monte, H. Savastano Jr., P. Mutje, C. Negro, Use of cellulose fibers from hemp core in fiber-cement production. Effect on flocculation, retention, drainage and product properties, Ind. Crops Prod. 39 (2012) 89-96.

[10] V. Agopyan, H. Savastano, V.M. John, M.A. Cincotto, Developments on vegetable fibre-cement based materials in Sao Paulo, Brazil: an overview, Cem. Concr. Compos. 27 (2005) 527-536.

[11] M. Jamshidi, A.A. Ramezanianpour, Laboratory and industrial investigations on hybrid of acrylic and glass short fibers as an alternative for substituting asbestos in Hatschek process, Constr. Build. Mater. 25 (2011) 298-302.
[12] M.A.S.D. Anjos, K. Ghavami, N.P. Barbosa, Compósitos à base de cimento reforçado com polpa celulósica de bambu. Parte II: uso de resíduos cerâmicos na matriz, Revista Brasileira de Engenharia Agrícola e Ambiental 7 (2003) 346349.

[13] M.D. Campbell, R.S.P. Coutts, Wood fiber-reinforced cement composites, J. Mater. Sci. 15 (1980) 1962-1970.

[14] H. Savastano, A. Turner, C. Mercer, W.O. Soboyejo, Mechanical behavior of cement-based materials reinforced with sisal fibers, J. Mater. Sci. 41 (2006) 6938-6948.

[15] M. Ardanuy, J. Claramunt, R. Arevalo, F. Pares, E. Aracri, T. Vidal, Nanofibrillated cellulose (nfc) as a potential reinforcement for high performance cement mortar composites, BioResources 7 (2012) 3883-3894.

[16] R.D. Toledo, K. Scrivener, G.L. England, K. Ghavami, Durability of alkalisensitive sisal and coconut fibres in cement mortar composites, Cem. Concr. Compos. 22 (2000) 127-143.

[17] B.J. Mohr, J.J. Biernacki, K.E. Kurtis, Supplementary cementitious materials for mitigating degradation of kraft pulp fiber-cement composites, Cem. Concr. Res. 37 (2007) 1531-1543.

[18] K. Bilba, M.A. Arsene, Silane treatment of bagasse fiber for reinforcement of cementitious composites, Compos. A Appl. Sci. Manuf. 39 (2008) 14881495.

[19] U. Weise, Hornification - mechanisms and terminology, Paperi Ja Puu-Paper and Timber 80 (1998) 110-115.

[20] G. Jayme, G. Hunger, The rearrangement of microfibrils in dried cellulose and the implication of this structure alteration on pulp properties, in: F. Bolam (Ed.), Fundamentals of Papermaking Fibres, BPBMA, Cambridge, 1957, pp. $263-270$.

[21] G. Jayme, Über die Reaktionsfähigkeit von Zellstoffen, Cellulosechemie 21 (1943) 73-86.

[22] C. Ackerman, L. Göttsching, H. Pakarinen, Papermaking potential of recycled fiber, in: L.A.P.H. Göttsching (Ed.), Recycled Fiber and Deiking, Papermaking Science and Technology, Finland, 2000, pp. 358-438.

[23] J. Diniz, M.H. Gil, J. Castro, Hornification - its origin and interpretation in wood pulps, Wood Sci. Technol. 37 (2004) 489-494.

[24] G. Jayme, Mikro-Quellungsmessungen an Zellstoffen, Wochenbl Papierfabr 6 (1944) 187-194.

[25] A.D. Bawden, R.P. Kibblewhite, Effects of multiple drying treatments on kraft fibre walls, J. Pulp Pap. Sci. 23 (1997) 340-346.

[26] J. Claramunt, M. Ardanuy, J.A. Garcia-Hortal, Effect of drying and rewetting cycles on the structure and physicochemical characteristics of softwood fibres for reinforcement of cementitious composites, Carbohydr. Polym. 79 (2010) 200-205.

[27] J. Claramunt, M. Ardanuy, J.A. Garcia-Hortal, R.D. Toledo, The hornification of vegetable fibers to improve the durability of cement mortar composites, Cem. Concr. Compos. 33 (2011) 586-595.

[28] ASTM C150/C150M-11, Standard Specification for Portland Cement, 2011.

[29] ISO 5263-1, Pulps - Laboratory Wet Disintegration - Part 1: Disintegration of Chemical Pulps, 2004.

[30] T UM 256, Water Retention Value (WRV), 2011.

[31] L.G.J.M.A. Segal, J.J. Creely, A.E. Martin, C.M. Conrad, An empirical method for estimating the degree of crystallinity of native cellulose using the X-ray diffractometer, Textile Res. J. 29 (1959) 786-794.

[32] T 230 om-04, Viscosity of Pulp (Capillary Viscometer Method), 2004.

[33] H. Savastano, P.G. Warden, R.S.P. Coutts, Brazilian waste fibres as reinforcement for cement-based composites, Cem. Concr. Compos. 22 (2000) 379-384.

[34] ASTM C 948-81, Standard. Dry and Wet Bulk Density, Water Absorption and Apparent Porosity of Thin Sections of Glass-Fiber Reinforced Concrete, 2009.

[35] Reunion internationale des laboratoires dessais et des recheches sur les materiaux et les constructions (rilem). rilem 49tfr: testing methods for fibre reinforced cement-based composites, Matériaux et Constructions 17 (1984) 441-456.

[36] EN 494, Standard. Fibre-Cement Profiled Sheets and Fittings for RoofingProducts Specification and Test Methods, 1994.

[37] Y. Chen, J. Wan, X. Zhang, Y. Ma, Y. Wang, Effect of beating on recycled properties of unbleached eucalyptus cellulose fiber, Carbohydr. Polym. 87 (2012) 730-736.

[38] E. Letkova, M. Letko, M. Vrska, Influence of recycling and temperature on the swelling ability of paper, Chem. Pap. 65 (2011) 822-828.

[39] A.M. Scallan, A.C. Tigerstrom, Swelling and elasticity of the cell-walls of pulp fibers, J. Pulp Pap. Sci. 18 (1992) 188-193.

[40] K. Somwang, T. Enomae, A. Isogai, F. Onabe, Changes in crystallinity and reswelling capability of pulp fibers by recycling treatment, Jpn. Tappi J. 56 (2002) 103-109.

[41] A. Sturcova, G.R. Davies, S.J. Eichhorn, Elastic modulus and stress-transfer properties of tunicate cellulose whiskers, Biomacromolecules 6 (2005) 10551061.

[42] F. Pouyet, C. Chirat, A. Potthast, D. Lachenal, Formation of carbonyl groups on cellulose during ozone treatment of pulp: consequences for pulp bleaching, Carbohydr. Polym. 109 (2014) 85-91.

[43] R.C. Howard, The effects of recycling on paper quality, J. Pulp Pap. Sci. 16 (1990) 143-149.

[44] J.L. Pehanich, P.R. Blankenhorn, M.R. Silsbee, Wood fiber surface treatment level effects on selected mechanical properties of wood fiber-cement composites, Cem. Concr. Res. 34 (2004) 59-65. 
[45] V.C. Correia, S.F. Santos, G. Mármol, A.A. Curvelo, H. Savastano, Potential of bamboo organosolv pulp as a reinforcing element in fiber-cement materials, Constr. Build. Mater. 72 (2014) 65-71.

[46] G.H.D. Tonoli, U.P. Rodrigues Filho, H. Savastano, J. Bras, M.N. Belgacem, F.A.R. Lahr, Cellulose modified fibres in cement based composites, Compos. A Appl. Sci. Manuf. 40 (2009) 2046-2053.

[47] NBR 5640, Standard. Structural Tile Fiber-Cement, Specification, 1995.

[48] H. Savastano, P.G. Warden, R.S.P. Coutts, Mechanically pulped sisal as reinforcement in cementitious matrices, Cem. Concr. Compos. 25 (2003) 311-319.
49] G.H.D. Tonoli, M.N. Belgacem, J. Bras, M.A.S. Pereira, F.A.R. Lahr, H. Savastano, Impact of bleaching pine fibre on the fibre/cement interface, J. Mater. Sci. 47 (2012) 4167-4177.

[50] NBR 15498, Standard. Flat Non-asbestos Cementitious Sheet - Requirements and Test Methods, 2007.

[51] A. Bentur, S.A.S. Akers, The microstructure and ageing of cellulose fibre reinforced cement composites cured in a normal environment, Int. J. Cem. Compos. Lightweight Concr. 11 (1989) 99-109. 